DISTRIBUTION STATEMENT A. Approved for public release; distribution is unlimited.

\title{
Development of the PCAD Model to Assess Biological Significance of Acoustic Disturbance
}

\author{
Daniel P. Costa, Ph.D. \\ Professor of Ecology and Evolutionary Biology \\ University of California \\ Santa Cruz, CA 95060 \\ phone: (831) 459-2786 fax: (831)459-3383 email: costa@ucsc.edu \\ Award Number: N00014-13-1-0134 \\ http://bio.research.ucsc.edu/people/costa/
}

\section{LONG-TERM GOALS}

Assessing the impact of disturbance events on cryptic or far-ranging marine mammal species is critically important to stakeholders who must balance project objectives with the environmental impacts of proposed activities. In recent years, considerable scientific interest in this topic has led to key discoveries relating to species-specific sensitivities, behavioral responses, and the physics of disturbance; however, we still lack the ability to predict the effect of potential disturbance events on a population. To better inform stakeholders about the likely consequences of a specific proposed activity, the PCAD (Population Consequences of Acoustic Disturbance) working group established a conceptual framework detailing the impact of disturbance events and how the effects cascade from individuals altering their behavior all the way to population-level demographic effects. The PCAD working group then developed a more rigorous analytical approach (New et al. 2014). These methods require substantial pre-existing knowledge of foraging patterns, life-history schedules, and demographics. Therefore, it is essential to use well-studied species to validate the approach. This is best accomplished by selecting species that are as similar as possible to target species and are also extremely well-studied. We identified northern elephant seals and Atlantic bottlenose dolphins as the best species to parameterize the PCAD model. These species represent two life-history extremes (capital and income breeders), have clear taxonomic separation (pinnipeds and cetaceans), and both species have been studied intensively for several decades, providing unprecedented demographic data. These factors imply that they likely respond to disturbance in unique ways and by developing models for each system, we can effectively bound the input parameters (and expected outputs) for other species of interest. This will be an essential step to eventually apply the model to species for which much less is known.

In the current project, we are focusing on several key opportunities. First, the combination of remarkable demographic data with "health" or body condition data will allow us for the first time to assess the effects of a disturbance event through all of the transfer functions of the PCAD model. This will be done with simulated, natural, and experimental disturbance events, giving us the power to estimate the effects of proposed disturbance activities while bounding the estimates with real-world values. We will also be focusing on some of the mechanistic aspects of the PCAD model. For example, by investigating fine-scale energetics via accelerometry or the role of the stress response in long-term 


\section{Report Documentation Page}

Form Approved

OMB No. 0704-0188

Public reporting burden for the collection of information is estimated to average 1 hour per response, including the time for reviewing instructions, searching existing data sources, gathering and maintaining the data needed, and completing and reviewing the collection of information. Send comments regarding this burden estimate or any other aspect of this collection of information,

including suggestions for reducing this burden, to Washington Headquarters Services, Directorate for Information Operations and Reports, 1215 Jefferson Davis Highway, Suite 1204, Arlington

VA 22202-4302. Respondents should be aware that notwithstanding any other provision of law, no person shall be subject to a penalty for failing to comply with a collection of information if it

does not display a currently valid OMB control number.

1. REPORT DATE

30 SEP 2014

4. TITLE AND SUBTITLE

Development of the PCAD Model to Assess Biological Significance of Acoustic Disturbance

6. $\operatorname{AUTHOR}(\mathrm{S})$

7. PERFORMING ORGANIZATION NAME(S) AND ADDRESS(ES)

University of California, Santa Cruz,Santa Cruz,CA,95060

9. SPONSORING/MONITORING AGENCY NAME(S) AND ADDRESS(ES)

12. DISTRIBUTION/AVAILABILITY STATEMENT

Approved for public release; distribution unlimited

13. SUPPLEMENTARY NOTES

14. ABSTRACT

15. SUBJECT TERMS

16. SECURITY CLASSIFICATION OF:

a. REPORT

unclassified b. ABSTRACT

unclassified c. THIS PAGE

unclassified
17. LIMITATION OF ABSTRACT

Same as Report (SAR)
3. DATES COVERED

00-00-2014 to 00-00-2014

5a. CONTRACT NUMBER

5b. GRANT NUMBER

5c. PROGRAM ELEMENT NUMBER

5d. PROJECT NUMBER

5e. TASK NUMBER

5f. WORK UNIT NUMBER

8. PERFORMING ORGANIZATION REPORT NUMBER

10. SPONSOR/MONITOR'S ACRONYM(S)

11. SPONSOR/MONITOR'S REPORT NUMBER(S) 
health and reproduction, we can begin developing tools that will enhance our confidence in the PCAD model for the data-limiting/cryptic species.

\section{OBJECTIVES}

While considerable progress has been made to quantify the transfer functions described above for southern elephant seals, our goals are to parameterize these models to make them applicable to other species and take the models one step further by simulating disturbances and quantifying how such disturbances may affect the population. Although this three-year project encompasses many aspects of the PCAD effort, we list only the objectives we have worked on during this second year.

1. Determine the relationship between adult female foraging success (energy gain) and natality and pup wean mass. Define the function of pup wean mass to pup survival.

2. Determine the ability of elephant seals to modify their foraging behavior (i.e. dive depth, dive frequency, trip duration, etc) to compensate for lost foraging opportunities, quantifying their resilience to disturbance. Specifically, analyze recently collected accelerometer data to estimate the energetic cost of displacement away from a disturbance.

3. In addition to the proposed objectives, we completed a study to compare our method for assessing body composition in the northern elephant seal (truncated cones) with labeled water techniques. This enables us to quantify the uncertainty associated with female condition metrics (lipid mass) that is a key link between disturbance events and demographic rates.

4. Organize and then incorporate Dr. Randy Wells' Sarasota Bay dolphin data set for analysis of an income breeding system.

\section{APPROACH}

\section{Body Composition Comparison Study}

Quantified uncertainty is becoming a standard metric provided to policy makers when deciding on protection levels for species (Regan et al. 2013). If physiological indicators are to become a part of models to predict the population outcome of disturbance, it is important to quantify the uncertainty in those metrics. In particular, lipid mass of female elephant seals has become a critical foraging success metric linked to reproductive rate. Pups' wean mass is also a function of maternal condition, and wean mass affects pup survival (McMahon et al. 2000, Crocker et al. 2001). To better understand the uncertainty in lipid mass estimates, this study compared results of several different methods to estimate percent lipid in elephant seals: elliptical truncated cones, circular truncated cones, and labeled water. We included use of two different ultrasound scanners (with and without images), accounted for the proportion lipid in skin, and quantified uncertainty in all techniques.

The Importance of Measurement Uncertainty in the Northern Elephant Seal PCAD Model

During Year 1 of this contract, we used long-term empirical data to develop a complete PCAD model and application for northern elephant seals (Costa et al. In press). By creating a simulated disturbance and using existing tracking data to understand how seals use the region, we can make informed predictions of the impact a disturbance will have at the individual level (lipid gain) and population level (e.g. pup survival rate and reproductive rate). However, models still need to account for measurement uncertainty in adult female lipid mass and wean mass. Pup wean mass is not known with certainty since pups are often weighed days after weaning. This analysis investigated how such 
variability affected functions between maternal condition, reproduction, pup wean mass, and pup survival.

\section{Energetic Cost of Displacement}

To understand the energetic cost of displacement, it is first necessary to understand how animals function normally. Specifically, quantifying the balance between how much food energy an individual requires to perform necessary life functions, and how much energy it expends in acquiring it, allows us to establish a physiological 'baseline' against which to compare the energetic costs associated with any changes in behavior. The next step is to then simulate disturbance, and measure the magnitudes of the behavioral and energetic avoidance responses - i.e., how did behavior change, and what were the associated energetic costs of those changes?

\section{Sarasota Bay Bottlenose Dolphin Analysis}

The first step to analyzing the bottlenose dolphin data is to create a mark-recapture model to estimate survival and reproductive rates. We have used a Cormack-Jolly-Seber model based on resights of animals both in and out of the main study area (Schwarz et al. 2013), limited to animals that are found within the main study area during at least $50 \%$ of the year (resident population). Given seasonal differences in calving, causes of mortality, and movement patterns, we estimated demographic rates on a quarterly basis starting May 1, 1992 through April 30, 2010 (latest available data). Another important aspect of this research is to find easy-to-measure physiological metrics that can be applied to dolphin populations where health assessments are not possible. Therefore, another initial step is to investigate correlations between respiration rates and known mortalities to see if respiration rates can be used as a metric of health.

\section{WORK COMPLETED}

\section{Body Composition Comparison Study}

During Year 1 of this contract, we collected both morphometric and tritiated water data from ten adult female seals. This year, we collected and analyzed data on skin thickness $(N=46)$ and proportion lipid content in both skin $(N=3)$ and blubber $(N=26)$ to estimate the proportion of total lipid found in those tissues. This refinement of the methods allows us to better understand previous results that assumed adipose tissue included the skin. A manuscript is complete and circulating with co-authors.

\section{The Importance of Measurement Uncertainty in the Northern Elephant Seal PCAD Model}

During the fall of 2013, uncertainty was quantified for all adult female blubber volume measurements, a precursor to estimating proportion lipid, based on the measurements from the above study. We also determined the uncertainty in pup wean mass from repeated measures of pups with known wean date out to 50 days post weaning. Uncertainty was incorporated in to Bayesian models that determine the relationships between maternal condition, reproduction, pup wean mass, and pup survival. Results were presented at the $20^{\text {th }}$ Biennial Conference on Marine Mammals, Dunedin, New Zealand, December 2013. A manuscript based on the findings will be submitted once the results of the body composition study have been published.

\section{Energetic Cost of Displacement}

To quantify the at-sea physiology of northern elephant seals under both normal and disturbed conditions, we used a two-stepped approach. First, we used a translocation paradigm (Andrews et al. 1997, Oliver et al. 1998, Webb et al. 1998, Costa et al. 2003) and the doubly-labeled water method (Nagy 1983, Costa 1987, Speakman 1997, Sparling et al. 2008) to measure the at-sea cost of 
locomotion in 12 juvenile seals (Maresh et al. 2014). Then, we were able to apply this knowledge to 23 adult female seals tagged with accelerometers that monitored fine-scale locomotion behavior.

Collectively, this information allowed us to construct activity-energy budgets for elephant seals during their foraging migrations, giving us insight into not only their energy requirments, but also into the foraging behaviors that allow them to stay in positive energy balance (Maresh et al., in review).

During the studies on both juveniles and adult seals, we were able to simulate disturbance by tagging some individuals (juveniles $\mathrm{N}=11$, adults $\mathrm{N}=3$ ) with instrumentation that artificially increased transport costs, thereby causing increased swimming effort in ways that are comparable to those measured under scenarios of decreased prey availability under standard locomotion (Cornick et al. 2006). Our studies were unique in their ability to couple both behavioral and energetic measurements on wild animals in situ.

$\underline{\text { Sarasota Bay Bottlenose Dolphin Analysis }}$

In March 2014, Dr. Randy Wells provided quarterly mark-recapture data to Dr. Lisa Schwarz on 134 females, 122 males, and 80 of unknown sex. We have investigated survival as a function of age, sex, and an annual red tide index. Dr. Wells is assembling annual health metric data from health assessments (body mass index and white blood cell count) to compare with annual survival rate estimates and red tide. Quarterly movement probabilities in and out of the area were estimated by year. Dr. Schwarz is developing an additional mark-recapture model to incorporate reproductive rates. Dr. Katie McHugh from the Sarasota Dolphin Research Program compiled data on breathing rates of known dead or rescued individuals $(N=10)$.

\section{RESULTS}

\section{Body Composition Comparison Study}

Northern elephant seals are not circular on land. Instead, elliptical cones produced smaller volume estimates and larger total body density estimates. Skin may account for a high proportion of what is often defined as blubber depth in ultrasound readings (from the surface of the animal through the blubber layer). Using the incorrect but often-used assumption that skin has the same fraction lipid as blubber, proportion lipid estimates are biased high by $62 \pm 18 \%$ SD. Proportion lipid estimates using elliptical cones (accounting for skin) had lower uncertainty (SD: $0.015 \pm 0.003$ ) than labeled water estimates (SD: $0.027 \pm 0.007)$. Truncated cones uncertainty may be reduced by measuring skin depth, blubber density, and fraction lipid in blubber for individual animals.

\section{The Importance of Measurement Uncertainty in the Northern Elephant Seal PCAD Model}

Measurement uncertainty had little-to-no effect on the relationship between maternal condition and pup wean mass or the function defining pup survival with respect to wean mass. Pup wean mass depends on many factors other than maternal condition, so process variance is high for this relationship, and measurement uncertainty accounted for little of the process variance. Uncertainty in first year survival estimates is primarily due to low resight probabilities, so wean mass uncertainty did not change the results in the wean mass - survival relationship. Uncertainty in maternal condition slightly changed the rate at which reproduction increased with better maternal condition since the scale of the measurement uncertainty is small compared to the scale of the relationship.

\section{Energetic Cost of Displacement}

In our study on translocated juveniles, we found that the cost of each flipper stroke (Williams et al. 2004) during standard locomotion was approximately $2.58 \mathrm{~J} \mathrm{~kg}^{-1}$. Field metabolic rates were $122.5 \mathrm{~kJ}$ 
$\mathrm{kg}^{-1}$ day $^{-1}$ and $79.8 \mathrm{~kJ} \mathrm{~kg}^{-1}$ day $^{-1}$ for one- and two-year-old seals, respectively. Energetically, elephant seals were sensitive to increased transport costs, with the cost per stroke increasing by $71 \%$ and the field metabolic rate increasing by $60 \%$ under the disturbance scenario. These extra costs were reflected in changes in some of their diving behaviors, most notably a $46 \%$ increase in time spent at the surface resting between dives.

In our study on adult females, we found that elephant seals have low field metabolic rates ( $\mathrm{mean}=73.6$ $\mathrm{kJ} \mathrm{kg}^{-1} \mathrm{~d}^{-1}$ and $56.1 \mathrm{~kJ} \mathrm{~kg}^{-1} \mathrm{~d}^{-1}$ during their short and long migrations, respectively; Fig. 1) that are maintained to some extent by keeping locomotion costs low - elephant seals allocated only $4 \%$ of totally energy intake towards fueling locomotion (Fig. 2). For the three individuals carrying the extra instrumentation, the increased swimming effort increased locomotion costs by $400 \%$ (Fig. 2 ), and overall FMRs increased by $22 \%$. Seals under the simulated disturbance scenario allocated roughly $16 \%$ of total energy intake towards locomotion, enough to upset energy balance in these individuals. Seals under the drag scenario were only able to allocate one-third as much of their prey energy intake toward their own growth compared to seals swimming without the added transport costs, and these individuals returned from their foraging migrations noticeably undersized and nutritionally stressed. Extra costs under the disturbance scenario were reflected behaviorally as a $25 \%$ increase in flipper stroking rate (Fig. 3) and, for one individual, extended time spent at sea.

Sarasota Bay Bottlenose Dolphin Analysis

A Siler model was fit to estimate survival as a function of age. However, a simpler model separating survival rates by age classes ( 1 year, $2-7$ years, and $8+$ years old) resulted in a better fit to the data and produced similar population growth rate estimates as the more complex Siler model. Therefore, we continued analyses with three age classes. Male and female bottlenose dolphins have similar survival rates by age. Movement patterns indicate a general move in to the main study area in 1996 and 1997, coincident with the ban on net fishing. During a severe red tide event in 2005, resident animals were less likely to move in to and more likely to move out of the main study area. Preliminary results suggest annual survival rates for both $2-7$ year olds and $8+$ year olds are correlated with red tide events the previous year in Sarasota Bay $(N=14$ years $)$.

After a thorough review of all data, sample size is too small $(N=10)$ to determine if respiration rate could be used as a metric for health. In addition, most data are on animals that were entangled $(N=6)$, making it unclear if potential changes in respiration are an indication of poor health or a symptom of increased drag leading to higher metabolic rates. Data are available for four animals prior, during, and after rescue.

\section{IMPACT/APPLICATIONS}

\section{Body Composition Comparison Study}

Lipid mass and body condition are important metrics in bioenergetics and physiological studies. They can also link foraging success and demographic rates, making them key components of models that predict population-level outcomes of environmental change. Therefore, it is important to incorporate uncertainty in physiological indicators if results will lead to species management decisions. Results indicate that future research should incorporate uncertainty in this important physiological metric and should account for skin properties and elliptical shape when using the truncated cones method. 
The Importance of Measurement Uncertainty in the Northern Elephant Seal PCAD Model

While measurement uncertainty did not strongly affect the northern elephant seal PCAD model, such a conclusion would not have been possible before measuring the uncertainty and testing the models. Conservation modeling is constantly under scrutiny, and the northern elephant seal example shows how measurement uncertainty can be determined and incorporated in to such models.

\section{Energetic Cost of Displacement}

Results suggest that under normal circumstances, elephant seals employ a foraging strategy of extreme energy economy that requires keeping costs low. They are able to do this partly by expending very little energy toward locomotion. However, even a small increase in swimming effort, if chronic, can compound in a way that upsets their efficient strategy, causing elephant seals to enter into negative energy balance.

\section{Sarasota Bay Bottlenose Dolphin Analysis}

Using red tide as a metric for disturbance will allow us to complete a PCAD model for bottlenose dolphins based on unique, long-term empirical data. The results of this analysis will aid in understanding the relationships we might see for species, or other bottlenose dolphin populations, for which we have very little data and may aid in determining the most effective type of data to collect to determine the population consequences of disturbance.

\section{RELATED PROJECTS}

Application of the PCAD Model to the California Gray Whale, Integration of Existing Data and Towards a Quantitative Assessment of Biological Significance of Acoustic Disturbance. Joint Award Shell Oil and ExxonMobil Oil Companies. Nov 1 2012-Sept 31 2013. \$120,000.

Environmental perturbations, behavioral change, and population response in a long-term northern elephant seal study. ONR N00014-10-1-0356.

A bioenergetic model to estimate the population consequences of disturbance. The E\&P Sound and Marine Life Joint Industry Programme. September 2014 - August 2017. \$1,050,780.

\section{REFERENCES}

Andrews, R. D., D. R. Jones, , J. D. Williams, P. H. Thorson, G. W. Oliver, D. P. Costa, and B. J. LeBoeuf. 1997. Heart rates of northern elephant seals diving at sea and resting on the beach. Journal of Experimental Biology 200:2083-2095.

Cornick, L. A., S. D. Inglis, K. Willis, and M. Horning. 2006. Effects of increased swimming costs on foraging behavior and efficiency of captive Steller sea lions: evidence for behavioral plasticity in the recovery phase of dives. Journal of Experimental Marine Biology and Ecology 333:306-314.

Costa, D. P. 1987. Isotopic methods for quantifying material and energy intake of free-ranging marine mammals. In Approaches to Marine Mammal Energetics, Vol. 1, pp. 43-66.

Costa, D. P., D. E. Crocker, J. Gedamke, P. M. Webb, D. S. Houser, S. B. Blackwell, D. Waples, S. A. Hayes and B. J. Le Boeuf. 2003. The effect of a low-frequency sound source (acoustic thermometry of the ocean climate) on the diving behavior of juvenile northern elephant seals, Mirounga angustirostris. Journal of the Acoustic Society of America 113:1155-1165. 
Costa, D. P., L. K. Schwarz, P. W. Robinson, R. S. Schick, P. A. Morris, R. S. Condit, D. E. Crocker, and A. M. Kilpatrick. In press. A bioenergetics approach to understanding population consequences of disturbance: elephant seals as a model system. The Effects of Noise on Aquatic Life II. Springer.

Crocker, D. E., J. D. Williams, D. P. Costa, and B. J. Le Boeuf. 2001. Maternal traits and reproductive effort in northern elephant seals. Ecology 82:3541-3555.

Maresh, J. L., S. E. Simmons, D. E. Crocker, B. I. McDonald, T. M. Williams, and D. P. Costa. 2014. Free-swimming northern elephant seals have low field metabolic rates that are sensitive to an increased cost of transport. Journal of Experimental Biology (in press).

Maresh, J. L., T. Adachi, A. Takahashi, Y. Naito, D. E. Crocker, T. M. Williams, and D. P. Costa (in review). Summing the strokes: extreme energy economy in a large marine carnivore. Functional Ecology

McMahon, C. R., H. R. Burton, and M. N. Bester. 2000. Weaning mass and the future survival of juvenile southern elephant seals, Mirounga leonina, at Macquarie Island. Antarctic Science 12:149-153.

Nagy, K. A. (1983). The Doubly Labeled Water (3HH18O) Method: A Guide to its Use. Los Angeles: UCLA Publ. No. 12-1417

New, L. F., J. S. Clark, D. P. Costa, E. Fleishman, M. A. Hindell, T. Klanjšček, D. Lusseau, S. Kraus, C. R. McMahon, P. W. Robinson, R. S. Schick, L. K. Schwarz, S. E. Simmons, L. Thomas, P. Tyack, and J. Harwood. 2014. Using short-term measures of behaviour to estimate long-term fitness of southern elephant seals. Marine Ecology Progress Series 496:99 - 108.

Oliver, G. W., P. A. Morris, P. H. Thorson, and B. J. Le Boeuf. 1998. Homing behavior of juvenile northern elephant seals. Marine Mammal Science 14:245-256.

Regan, T. J., B. L. Taylor, G. G. Thompson, J. F. Cochrane, K. Ralls, M. C. Runge, and R. Merrick. 2013. Testing Decision Rules for Categorizing Species' Extinction Risk to Help Develop Quantitative Listing Criteria for the US Endangered Species Act. Conservation Biology 27:821831.

Schwarz, L. K., M. Goebel, D. Costa, and A. M. Kilpatrick. 2013. Top-down and bottom-up influences on demographic rates of Antarctic fur seals (Arctocephalus gazella). Journal of Animal Ecology $82: 903-911$.

Sparling, C. E., D. Thompson, M. A. Fedak, S. L. Gallon, and J. R. Speakman. 2008. Estimating field metabolic rates of pinnipeds: doubly labelled water gets the seal of approval. Functional Ecology 22:245-254.

Speakman, J. R. 1997. Doubly Labelled Water: Theory and Practice. London; New York: Chapman \& Hall

Webb, P. M., D. E. Crocker, S. B. Blackwell, D. P. Costa, and B. J. Le Boeuf. 1998b. Effects of buoyancy on the diving behavior of northern elephant seals. Journal of Experimental Biology 201:2349-2358.

Williams, T. M., L. A. Fuiman, M. Horning, and R. W. Davis. 2004a. The cost of foraging by a marine predator, the Weddell seal Leptonychotes weddellii: pricing by the stroke. Journal of Experimental Biology 207:973-982. 


\section{PUBLICATIONS}

Brooks, C. M., J. B. Weller, K. Gjerde, R. Sumaila, J. Ardron, N. C. Ban, D. Freestone, S. Seto, S. Unger, D. P. Costa, K. Fisher, L. B. Crowder, P. Halpin, and A. Boustany. 2014. Challenging the 'Right to Fish' in a Fast-Changing Ocean. Stanford Environmental Law Journal 33:289-324.

Costa, D. P., L. Schwarz, P. Robinson, R. S. Schick, P. A. Morris, R. Condit, D. E. Crocker, and A. M. Kilpatrick. in press. A Bioenergetics Approach to Understanding the Population Consequences of Disturbance: Elephant seals as a Model System.

Fowler, M. A., C. Debier, E. Mignolet, C. Linard, D. E. Crocker, and D. P. Costa. 2014. Fatty acid mobilization and comparison to milk fatty acid content in northern elephant seals. Journal of Comparative Physiology B-Biochemical Systemic and Environmental Physiology 184:125-135.

Hobday, A. J., S. M. Maxwell, J. Forgie, J. McDonald, M. Darby, K. Seto, H. Bailey, S. J. Bograd, D. K. Briscoe, D. P. Costa, L. B. Crowder, D. C. Dunn, S. Fossette, P. N. Halpin, J. R. Hartog, E. L. Hazen, B. G. Lascelles, R. L. Lewison, G. Poulos, and P. A. 2014. Dynamic Ocean Management: Integrating Scientific and Technological Capacity with Law, Policy, and Management. Stanford Environmental Law Journal 33:125-165.

Hobday, A. J., J. W. Young, O. Abe, D. P. Costa, R. K. Cowen, K. Evans, M. A. Gasalla, R. Kloser, O. Maury, and K. C. Weng. 2013. Climate impacts and oceanic top predators: moving from impacts to adaptation in oceanic systems. Reviews in Fish Biology and Fisheries 23:537-546.

Hückstädt, L. A., R. A. Quiñones, M. Sepúlveda, and D. P. Costa. 2013. Movement and diving patterns of juvenile male South American sea lions off the coast of central Chile. Marine Mammal Science:n/a-n/a.

Hückstädt, L. A., R. A. Quiñones, M. Sepúlveda, and D. P. Costa. 2014. Movement and diving patterns of juvenile male South American sea lions off the coast of central Chile. Marine Mammal Science 30:1175-1183.

Jeglinski, J. W., K. T. Goetz, C. Werner, D. P. Costa, and F. Trillmich. 2013. Same size--same niche? Foraging niche separation between sympatric juvenile Galapagos sea lions and adult Galapagos fur seals. Journal of Animal Ecology 82:694-706.

Louis, C., A. C. Dirtu, M. Stas, Y. Guiot, G. Malarvannan, K. Das, D. P. Costa, D. E. Crocker, A. Covaci, and C. Debier. 2014. Mobilisation of lipophilic pollutants from blubber in northern elephant seal pups (Mirounga angustirostris) during the post-weaning fast. Environmental Research 132:438-448.

Maresh, J. L., S. E. Simmons, D. E. Crocker, B. I. McDonald, T. M. Williams, and D. P. Costa. 2014. Free-swimming northern elephant seals have low field metabolic rates that are sensitive to an increased cost of transport. The Journal of Experimental Biology 217:1485-1495.

Maxwell, S. M., E. L. Hazen, S. J. Bograd, B. S. Halpern, G. A. Breed, B. Nickel, N. M. Teutschel, L. B. Crowder, S. Benson, P. H. Dutton, H. Bailey, M. A. Kappes, C. E. Kuhn, M. J. Weise, B. Mate, S. A. Shaffer, J. L. Hassrick, R. W. Henry, L. Irvine, B. I. McDonald, P. W. Robinson, B. A. Block, and D. P. Costa. 2013. Cumulative human impacts on marine predators. Nature communications 4:2688.

Meir, J. U., P. W. Robinson, L. I. Vilchis, G. L. Kooyman, D. P. Costa, and P. J. Ponganis. 2013. Blood oxygen depletion is independent of dive function in a deep diving vertebrate, the northern elephant seal. PLoS ONE 8:e83248. 
Naito, Y., D. P. Costa, T. Adachi, P. W. Robinson, M. Fowler, A. Takahashi, and C. Franklin. 2013. Unravelling the mysteries of a mesopelagic diet: a large apex predator specializes on small prey. Functional Ecology 27:710-717.

New, L. F., J. S. Clark, D. P. Costa, E. Fleishman, M. A. Hindell, T. Klanjšček, D. Lusseau, S. Kraus, C. R. McMahon, P. W. Robinson, R. S. Schick, L. K. Schwarz, S. E. Simmons, L. Thomas, P. Tyack, and J. Harwood. 2014. Using short-term measures of behaviour to estimate long-term fitness of southern elephant seals. Marine Ecology Progress Series 496:99-108.

New, L. F., D. J. Moretti, S. K. Hooker, D. P. Costa, and S. E. Simmons. 2013. Using energetic models to investigate the survival and reproduction of beaked whales (family Ziphiidae). PLoS ONE 8:e68725.

Peterson, S. H., J. L. Hassrick, A. Lafontaine, J. P. Thome, D. E. Crocker, C. Debier, and D. P. Costa. 2014. Effects of age, adipose percent, and reproduction on PCB concentrations and profiles in an extreme fasting North Pacific marine mammal. PLoS ONE 9:e96191.

Roman, J., J. A. Estes, L. Morissette, C. Smith, D. Costa, J. McCarthy, J. B. Nation, S. Nicol, A. Pershing, and V. Smetacek. 2014. Whales as marine ecosystem engineers. Frontiers in Ecology and the Environment 12:377-385.

Schick, R. S., L. F. New, L. Thomas, D. P. Costa, M. A. Hindell, C. R. McMahon, P. W. Robinson, S. E. Simmons, M. Thums, J. Harwood, and J. S. Clark. 2013. Estimating resource acquisition and at-sea body condition of a marine predator. Journal of Animal Ecology 82:1300-1315.

Sepulveda, M., S. D. Newsome, G. Pavez, D. Oliva, D. P. Costa, and L. A. Hückstädt. in review. Using satellite tracking and isotopic information to characterize the impact of south american sea lions on salmonid aquaculture in southern Chile. PLoS ONE. 